Canadian Journal of Family and Youth, 14(1), 2022, pp. 147-161

ISSN 1718-9748@ University of Alberta

http://ejournals,library,ualberta.ca/index/php/cjfy

\title{
Issues and Challenges of, Factors that Affect, and the Primary Influences of Parents' Decisions to Vaccinate their Adolescents: A Case of a Local National High School in Cagayan de Oro City, Philippines
}

\author{
Jenny J. Casiño and Angelo Mark P. Walag
}

\begin{abstract}
Vaccines are considered to be the center of the prevention and management of viral diseases. Even with the wide acceptance that vaccines are safe, vaccine hesitancy is still rampant in various parts of the world. Several historical, social, religious, and moral factors were identified and observed to have influence parent's vaccine acceptance or hesitance. Parent's vaccine hesitance or acceptance is crucial since adolescents constitute the ideal group for immunization. This study aims to uncover the issues and challenges of parents on vaccination, the factors that affect their decision to vaccinate their children, and parents' primary influences to vaccinate their children. A descriptive-survey research design utilizing a questionnaire floated to parents of adolescents in a local high school. It was found out that the level of education and type of occupation was significantly associated with parent's decision to vaccinate their children. The major issue and challenge of parents toward vaccination is that they don't find vaccines important and have a high level of distrust towards the government's health agency and medical professionals. The primary factor affecting their decision-making is the negative news on vaccination and vaccine safety. Respondents also reported that even they distrust the government's health agency, they still consider it influential towards their vaccine decision-making. With this, it is recommended that efforts be strengthened in restoring the public's trust towards the government health agency to address vaccine hesitancy.
\end{abstract}

Keywords: Parent's vaccine hesitancy, vaccination program, vaccine acceptance, vaccine intervention program, vaccine safety 
Jenny J. Casiño is an Academic Coordinator and Science Teacher of Puerto National High School, Cagayan de Oro City, Philippines. Her research interests include science education, chemistry education, science communication, vaccine intervention, and vaccine education. Her most recent publication is: Casinio, J. J., \& Walag, A. M. P. (2020). Design and Development of a Science Literacy Material on Vaccination as an Intervention Campaign for Parents of High School Students in the Philippines. American Journal of Educational Research, 8(10), 762-766.

Angelo Mark P. Walag is an Assistant Professor of the Department of Science Education, University of Science and Technology of Southern Philippines, Cagayan de Oro City, Philippines. His main research interests are in science education, science communication, teenage pregnancy, adolescent education, and social sciences. His most recent publications include: Walag, A. M. P., Gadian, D. C. C., Walag, I. P., Merlas, M. A. G., Larosa, L. V., Lumantas, S. P., \& Salugsugan-Joaquin, M. C. (2018). Adolescent pregnancy and family history of adolescent pregnancy in El Salvador City, Philippines. Canadian Journal of Family and Youth/Le Journal Canadien de Famille et de La Jeunesse, 10(1), 259-274; and Casino, J. J., \& Walag, A. M. P. (2020). Design and Development of a Science Literacy Material on Vaccination as an Intervention Campaign for Parents of High School Students in the Philippines. American Journal of Educational Research, 8(10), 762-766. 


\section{Introduction}

Measles (rubeola) is an extremely communicable acute viral infection that can cause serious implications (Bester, 2016). The measles virus spreads from one person to another through respiratory droplets caused by excessive coughing, sneezing, or direct contact (de Vries et al., 2012). The average person infected with the measles virus can infect twelve to eighteen other people if all are in close contact and susceptible (Plotkin et al., 2018). It is classified as a member of the genus Morbillivirus in the paramyxoviridae family (Abad \& Safdar, 2015). The virus that causes this infection is endemic in most of the world and has been the leading cause of death among young children. Humans are the only known host of this virus. The virus triggers an aggressive immune response involving both humoral and cellular immune systems (Buchanan \& Bonthius, 2012).

In 2000, the United States was declared to be free from measles, although it continues to circulate in the region (Hall et al., 2017). In 2014, the US experienced the most significant outbreak where most of the cases were internationally imported from the European Region. In the Philippines, on the other hand, the country reported 18,000 cases in 2018 compared to 2,400 cases in 2017 (Dyer, 2019). The high prevalence of measles cases in Manila was attributed to the fact that the city includes a large population living in small suburbs, allowing the virus to easily and rapidly spread (Ochani et al., 2019).

Vaccination has been the center in preventing and managing the measles disease burden and measles outbreak (Bester, 2016). An overall MMR (measles, mumps, and rubella) vaccine coverage has been highly noted to interrupt the endemic transmission of measles and eliminate it. From 2000 to 2017, an estimated 21.1 million deaths were prevented, reducing the global deaths by $80 \%$ due to vaccine administration (Ochani et al., 2019). In the Philippines, the rapid drop in vaccination rate, from $73 \%$ in 2017 to $55 \%$ in 2018 , has been blamed for the measles outbreak's reemergence. A similar observation was noted in 2013-2014 measle resurgence due to poor implementation of measles elimination programs (Takashima et al., 2015). The same also was recorded in Cordillera, Northern Philippines, where an outbreak in 2013 occurred in an area with low immunization coverage (Ching et al., 2016).

The low vaccination turnout has been blamed on the lack of public confidence in the government's immunization program (Ochani et al., 2019). More so, low vaccination uptake in children has been primarily due to the parent's hesitancy to have their children vaccinated (Bester, 2016). This hesitancy arose due to the deaths resulted from the Dengvaxia vaccine, which gave rise to a severe form of dengue and health consequences in people who have never been affected by the flavivirus (Casino \& Walag, 2020). Additionally, parents were noted to avoid vaccinating their children due to a misconception that the MMR vaccine is linked with autism (Ochani et al., 2019). Vaccine hesitancy is so prevalent that even those who did not receive vaccination reject it (Yaqub et al., 2014).

There are several reasons why parents hesitate to have their child vaccinated. One of the major reasons almost all parents hesitate to vaccinate their children is the vaccine's safety concern. Several determinants of vaccine hesitancy were identified (Giambi et al., 2018). Some of these determinants are (1) not having received by the family pediatrician a recommendation to vaccinate their children, (2) having received conflicting opinions on vaccination by health professionals, (3) 
having met parents who have children who experienced adverse effects after vaccine administration, and (4) those who use alternative and complementary medicine. Overall, vaccine hesitancy is a multi-faceted problem stemming from issues on knowledge and information, past experiences, perceived importance, risk perception, and trust, subjective norm, and religions and moral convictions (Dubé et al., 2013). Parental knowledge, beliefs, and attitudes towards vaccination are critical determinants of vaccine acceptance and vaccine hesitancy (Larson Williams et al., 2019). Also, parent's vaccine acceptance is crucial since adolescents constitute the ideal group for immunization (Davis et al., 2004). More so, no paper has yet examined the factors that contribute to vaccine hesitancy in the Philippines. For this reason, this study aims to uncover the issues and challenges of parents on the vaccination program, the factors that affect their decision to vaccinate their children, and the parent's primary influence to vaccinate their children.

\section{Methods}

\section{Research Design}

This research utilized a descriptive survey research design to uncover the issues and challenges of parents on vaccination, the factors that affect their decision to vaccinate their children, and parents' primary influences to vaccinate their children. Descriptive research design best describes the study population's characteristics or a particular phenomenon being studied (Walag \& Fajardo, 2020). Data was gathered from parents of high school students in Puerto National High School using a researcher-made instrument. The research questionnaire was administered to parents during a parent-teacher conference organized by the school. Sufficient time was given to the respondents to answer the questionnaire, and questions were all addressed by the researchers on-site. Appropriate permissions from school administration, local government, and research ethics committee were acquired prior to the conduct of the study. The research objectives were then explained to the respondents, and participation in the study was optional. The highest priority was given to ensure the confidentiality and anonymity of all questionnaires and responses.

\section{Research Instrument}

The researcher-made instrument was composed of the demographic characteristics of parents, the issues and challenges of parents (ICP), factors that affect their decision (FAD), and parent's primary influences (PPI). The components of the instruments were constructed based from an exhaustive literature review. The ICP, FAD, and PPI were developed utilizing a Liker-scale. The instrument was subjected to face and content validity by sociologists, medical experts, and assessment professors. The instrument was pilot-tested and found to have an internal consistency of $\alpha=0.72$ using Cronbach's Alpha. 


\section{Study Population}

The study population is the parents of Puerto National High School, Cagayan de Oro City. From the study population, the sample size was calculated using a method from the literature (Walag et al., 2018). The sample size calculated was 127 , but only 100 agreed to participate in the study, thus having a retrieval rate of $78.74 \%$, which is already acceptable for social science research. The demographics of the respondents are summarized in Table 1 in the next section.

\section{Statistical Analysis}

Descriptive statistics were employed to determine the frequency, mean, and standard deviation of all demographic characteristics and dependent variables. Chi-Square was used to measure the association between the demographic characteristics and their decision to vaccinate their children (Davis et al., 2004). Significance was tested at 0.05 level in all Chi-Square performed. All statistical analyses were performed using Minitab Software $17^{\text {th }}$ Edition. For the test of associations not meeting the conditions of Chi-Square, Yates' correction for continuity was used.

\section{Results and Discussion}

\section{Demographics Characteristics and their Acceptance of the MMR Vaccine}

A total of 127 parents of Grade 7 students were reached out to during a parent-teacher conference organized by the school. Only 100 (78.74\% retrieval rate) parents agreed to participate in the study after being informed of the research objectives and other ethical considerations. Their demographic characteristics are summarized in Table 1 . The majority of the parents are between ages 31 to 50 years old, with at least a high school level education, works in the agricultural sector or unemployed, and an average monthly income of Php 5,000 to 8,000.

The respondents' demographics characteristics were compared based on whether they wanted their child to receive the MMR vaccine (Table 1). Significant differences were noted in terms of educational attainment and occupation. The difference between educational attainment is expected since, in the study on vaccine hesitancy of annual influenza vaccine, the odds of being vaccine-hesitant was significantly greater for parents with less than a college education (Cunningham et al., 2018). More so, the mother's educational level contributes to the differences in the completion or non-completion of immunization series by the age of 18 months, where less educated and poor mothers were more diligent in ensuring that their children receive complete immunizations (Kim et al., 2007). On the contrary, educational level was not associated with vaccine hesitancy in Malaysia (Mohd Azizi et al., 2017). Although differing results, this still implies that the level of education can be used as a predictor of whether parents will have their children vaccinated or not.

Parents' employment was also noted to be correlated to whether they will vaccinate their child or not. In a multicultural study in Malaysia, vaccine hesitancy was associated with unemploy- 
ment, younger parents, fewer children, and non-Muslim (Mohd Azizi et al., 2017). It is also noteworthy to report that the income and age were not found to be associated with the decision to vaccinate their children as otherwise reported in the literature (Larson et al., 2014; Mohd Azizi et al., 2017).

Table 1:

Demographic Characteristics of Respondents based on MMR Vaccine Acceptance (n=100)

"Do you want your child to receive the MMR vaccine?"

Demographic characteristics
Yes $\left(n_{y}=49\right)$
No $\left(\mathrm{n}_{\mathrm{n}}=51\right)$
p-value $e^{a, b}$

Age (years)

26-30

31-40

41-50

51 and above

Educational Attainment

Primary School level

High School level

College level

College Graduate

Occupation (Industry)

Industrial/Factory

Academe

Health

Business

Agricultural
3

14

22

10

4

22

18

7 


$\begin{array}{lcc}\text { Transportation } & 2 & 3 \\ \text { Unemployed } & 15 & 17\end{array}$

Average Monthly Income (in Philippine Peso)

$\begin{array}{lccc}\text { Php 5,000 and below } & 10 & 12 & 0.7311^{\mathrm{a}} \\ \text { Php 5,001-8,000 } & 18 & 24 \\ \text { Php 8,001-11,000 } & 11 & 10 \\ \text { Php } 11,001-14,000 & 8 & 5 \\ \text { Php 14,001-17,000 } & 2 & 1\end{array}$

${ }^{\mathrm{a}} X^{2}$

'Yates' correction for continuity

$\mathrm{n}_{\mathrm{y}}$ - total number of those who answered yes

$\mathrm{n}_{\mathrm{n}}$ - total number of those who answered no

*Significant at 0.05 level

\section{Parent's Issues and Challenges towards vaccines}

The respondents were asked to their level of agreement towards the issues and challenges (ICP) enumerated in the questionnaire, which was based on exhaustive literature and existing themes from current news. Respondents agree most that "vaccination is not important". This could be because lack of information was associated with negative attitudes about vaccination and toward healthcare providers (Gust et al., 2005). Respondents also reported that the "vaccines provided by the Department of Health are expired". This is expected since, in 2017, much coverage was given to the Dengvaxia Scare in the country significantly affected the parent's trust in healthcare and medical professionals. A similar result was also found in Italy's national survey, where most respondents with high vaccine hesitancy reported not trusting pediatricians and public immunization services (Giambi et al., 2018). This is unfortunate since these healthcare professionals are supposed to be the most reliable source of information. Besides, a similar finding was noted where vaccine safety was the most reported reason for refusing vaccine vaccination and that there is a high level of mistrust in institutions responsible for vaccination (Giambi et al., 2018; Yaqub et al., 2014). 
Table 2:

\section{Parent's Issues and Challenges towards Vaccines and Vaccination Program}

\begin{tabular}{|c|c|c|c|}
\hline \multicolumn{2}{|c|}{ Parent's Issues and Challenges } & Mean & $\begin{array}{l}\text { Level of } \\
\text { Agreement }\end{array}$ \\
\hline \multicolumn{2}{|c|}{ 1. I am scared of the negative effect of vaccination } & 3.51 & Agree \\
\hline \multicolumn{2}{|c|}{ 2. I don't think vaccination is important } & 3.69 & Agree \\
\hline \multicolumn{2}{|c|}{ 3. I don't have any idea what these vaccines for } & 3.50 & Agree \\
\hline \multicolumn{2}{|c|}{ 4. Vaccinations are for infants and children only } & 3.61 & Agree \\
\hline \multicolumn{2}{|c|}{ 5. Vaccines will only make my kid sick } & 3.54 & Agree \\
\hline \multicolumn{2}{|c|}{ 6. I understand that these vaccines are not for free } & 3.28 & Undecided \\
\hline \multicolumn{2}{|c|}{ 7. Vaccines are not necessary to keep children healthy } & 3.54 & Agree \\
\hline \multicolumn{2}{|c|}{ 8. Vaccine will cause sexual impotence } & 3.54 & Agree \\
\hline \multicolumn{2}{|c|}{ 9. Vaccines from the Department of Health are expired } & 3.62 & Agree \\
\hline \multicolumn{2}{|c|}{ 10. My child might die because of vaccination } & 3.43 & Agree \\
\hline \multicolumn{4}{|l|}{ Legend: } \\
\hline $\begin{array}{l}4.21-5.00 \\
3.41-4.20 \\
2.61-3.40 \\
1.81-2.60 \\
1.00-1.80\end{array}$ & $\begin{array}{ll}5 & \text { Strongly Agree } \\
4 & \text { Agree } \\
3 & \text { Undecided } \\
2 & \text { Disagree } \\
1 & \text { Strongly Disagree }\end{array}$ & & \\
\hline
\end{tabular}

Factors that Contribute to a Parent's Refusal to Vaccinate their Adolescent Children

The factors that contribute to parent's refusal to vaccinate their adolescent children (FAD) were also explored through various literature, and current news, and respondents were asked to agree or disagree. Most of the respondents agreed that the number one factor affecting their refusal to provide consent is their "low confidence in the Department of Health". This is consistent with the previous section that one of the parent's vaccination issues is that the vaccines provided by the 
agency are expired. This result supports the notion that the credibility of institutions matters more than the information itself (Yaqub et al., 2014). This high level of distrust and low level of confidence towards the government's health agency may be attributed to the series of negative media coverage and mileage on the deaths related to the Dengvaxia mess. Not only the mainstream media but social media have also been found to have contributed to this mess. Numerous false articles linking vaccination to different diseases and disorders and even deaths flooded social media (Bernardo, 2019). Social media had also been noted to have a significant relationship with public doubts on vaccine safety (Wilson \& Wiysonge, 2020).

Respondents also agreed that the "negative news on vaccination" and "vaccines might cause harm" contributed to their refusal to vaccinate their children. The belief that vaccines might cause harm is expected since the most cited reason for vaccination attitude is the fear of the adverse side effect and vaccine safety (Yaqub et al., 2014).

Knowledge about vaccines and vaccination was also a contributor to parents' decision or vaccine hesitancy. Many studies have uncovered that parents who choose to vaccinate their child generally have limited knowledge of vaccination and vaccine-preventable diseases compared to those who refuse to vaccinate (Dubé et al., 2013). In several studies examining the barriers and facilitators to the maternal influenza vaccine, knowledge was a key factor in vaccine uptake (Bushar et al., 2017; Casino \& Walag, 2020; Yuen \& Tarrant, 2014).

Table 3:

Factors that Contribute to the Parent's Refusal in Providing Consent for the Vaccination of their Adolescent Children

\begin{tabular}{|c|c|c|c|c|}
\hline \multicolumn{2}{|r|}{ Factors Contribute to Parents' Refusal on } & \multirow[b]{2}{*}{ Mean } & Std. & \multirow{2}{*}{$\begin{array}{l}\text { Level of } \\
\text { Agreement }\end{array}$} \\
\hline & Vaccination & & Deviation & \\
\hline 1. & Lack of knowledge about the vaccines & 3.74 & 1.27 & Agree \\
\hline 2. & Negative news about vaccination & 3.81 & 1.23 & Agree \\
\hline 3. & Negative rumors about vaccinations & 3.74 & 1.40 & Agree \\
\hline 4. & Preference of alternative vaccines & 3.50 & 1.38 & Agree \\
\hline 5. & Low level of trust in the government & 3.62 & 1.38 & Agree \\
\hline 6. & Severity of vaccine-preventable diseases & 3.52 & 1.34 & Agree \\
\hline 7. & Vaccines might cause harm & 3.83 & 1.30 & Agree \\
\hline 8. & Disease susceptibility & 3.59 & 1.39 & Agree \\
\hline
\end{tabular}



9. Low confidence in Department of Health
10. Disease severity

Legend:

$\begin{array}{lll}4.21-5.00 & 5 & \text { Strongly Agree } \\ 3.41-4.20 & 4 & \text { Agree } \\ 2.61-3.40 & 3 & \text { Undecided } \\ 1.81-2.60 & 2 & \text { Disagree } \\ 1.00-1.80 & 1 & \text { Strongly Disagree }\end{array}$

\section{Parent's Primary Influence on Vaccination}

Parent's sources of influence whether they would vaccinate their adolescent children are summarized in Table 4. In the previous discussion, respondents report that they have high distrust towards the Philippine's Department of Health; they still consider the organization to be the most influential in their decision to vaccinate their children. This highlights the government's important role in promoting and restoring the public's trust and credibility of institutions involved in the vaccination program. Doctors are considered the most influential source of vaccination, but based on the results, respondents are undecided whether doctors and healthcare professionals influence their decision. This is not surprising as physicians reported increasing difficulties in building trustful relationships with patients (Yaqub et al., 2014).

It is also alarming to note that respondents report that TV News, radio news, newspaper, and social media are influential in their decision. Several reports also noted that social media may propagate misinformation by utilizing vivid narratives and powerful imagery (Chen \& Dredze, 2018; Robichaud et al., 2012; Shelby \& Ernst, 2013). The Philippines is not exempted from the use of vivid narratives and imagery, where several cases of child death, suspected to be caused by Dengvaxia vaccine, flooded major TV news channels, radio channels, and even on social media. This result is contradictory to the national survey conducted in Italy, where the majority of respondents reported considering family pediatricians and doctors of trust to be a reliable source of information compared to the web and their family/friends (Giambi et al., 2018). This difference in result could be a manifestation of the significant difference in the quality of healthcare in the Philippines and Italy. In 2019, there is one doctor for every 10,000 to 26,000 Filipinos (Bureau of Local Employment, 2019). The limited number of doctors could mean a limited number of patient consultations. This could be one of the reasons why respondents consider doctors not influential in their decision to vaccinate. 
Table 4:

Parent's Primary Influence on Vaccination

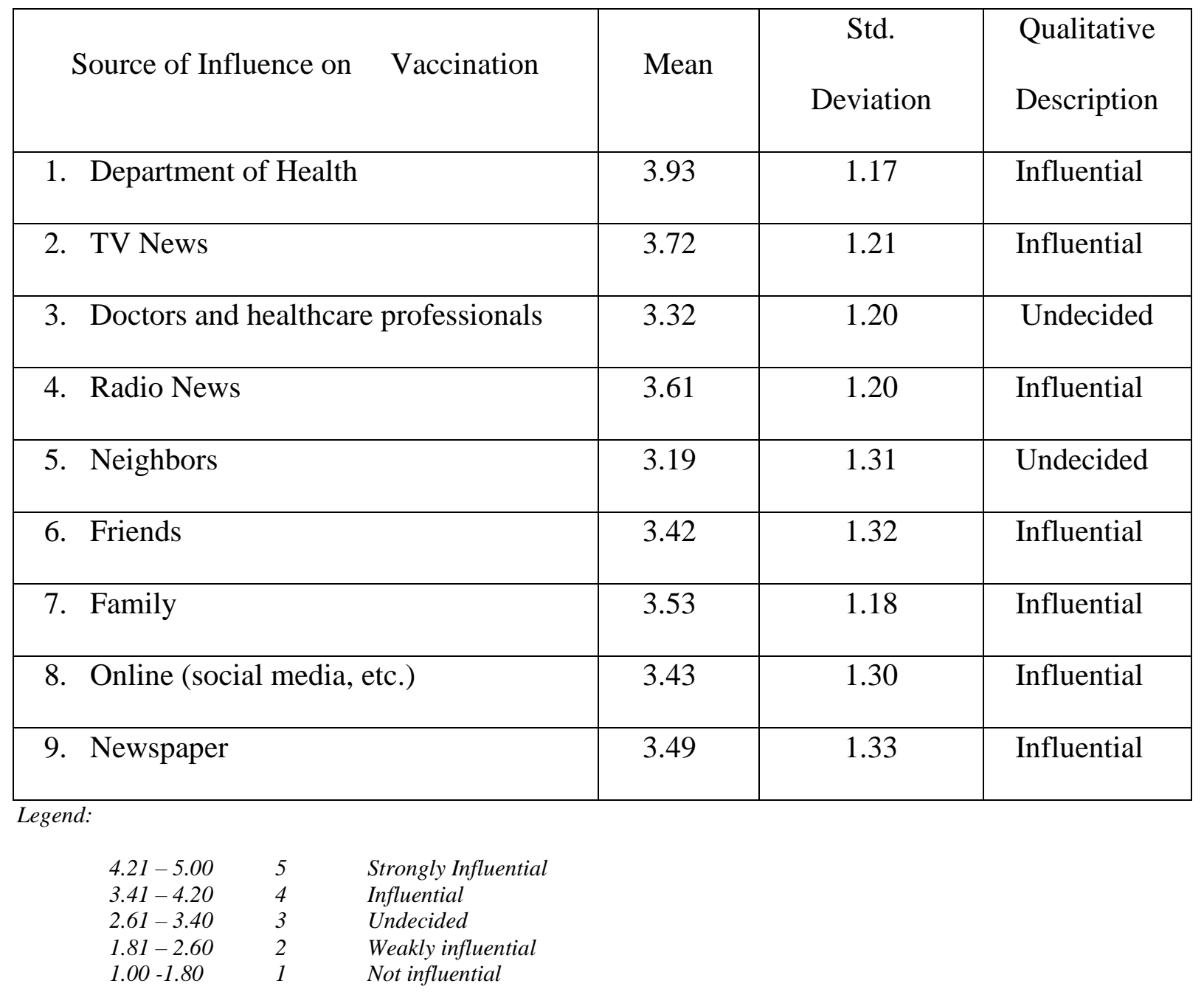

\section{Conclusion}

The issues and challenges, the factors that affect parents' primary influence to vaccinate their adolescent children, were determined using a descriptive survey research design using a researcher-made instrument. Just more than half of the parent-respondents reported that their adolescent children receive an MMR vaccine. Level of education and occupation type was also associated with the decision to vaccinate their children. This suggests that more thorough effort must be made to inform and educate those in the margin to limit vaccine hesitancy development. The main issue and challenge parents face when deciding to vaccinate their children is that they don't find vaccines are important and distrust the government agency responsible for vaccination. 
This lack of trust and fear towards vaccines' safety can be due to negative news they keep on hearing and seeing on major media platforms. These proliferate distrust towards the health agency and health professionals overall. Although there is a high level of distrust, parents still consider the health agency influential in their decision on vaccination. Moreover, media platform has been found to influence parents. The results highlight important variables to be considered when deciding on vaccine hesitancy intervention programs. The government must exert more effort in restoring the public's trust towards the vaccination program for it to be successful in eliminating recurring viral infections like measles. 


\section{References}

Abad, C. L., \& Safdar, N. (2015). The Reemergence of Measles. Current Infectious Disease Reports, 17(12), 51. https://doi.org/10.1007/s11908-015-0506-5

Bernardo, J. (2019, December 31). Social media as a health threat: Misinformation leads to poor vaccine coverage, measles and polio resurgence. ABS CBN News.

Bester, J. C. (2016). Measles and Measles Vaccination. JAMA Pediatrics, 170(12), 1209. https://doi.org/10.1001/jamapediatrics.2016.1787

Buchanan, R., \& Bonthius, D. J. (2012). Measles Virus and Associated Central Nervous System Sequelae. In Seminars in Pediatric Neurology. https://doi.org/10.1016/j.spen.2012.02.003

Bureau of Local Employment. (2019). Doctor (General Practitioner).

Bushar, J. A., Kendrick, J. S., Ding, H., Black, C. L., \& Greby, S. M. (2017). Text4baby Influenza Messaging and Influenza Vaccination Among Pregnant Women. American Journal of Preventive Medicine. https://doi.org/10.1016/j.amepre.2017.06.021

Casino, J., \& Walag, A. M. P. (2020). Design and Development of a Science Literacy Material on Vaccination as an Intervention Campaign for Parents of High School Students in the Philippines. American Journal of Educational Research, 8(10), 762-766. https://doi.org/10.12691/education-8-10-4

Chen, T., \& Dredze, M. (2018). Vaccine Images on Twitter: Analysis of What Images are Shared. Journal of Medical Internet Research, 20(4), e130. https://doi.org/10.2196/jmir.8221

Ching, P. K., Zapanta, M. J., de Los Reyes, V. C., Tayag, E., \& Magpantay, R. (2016). Investigation of a measles outbreak in Cordillera, Northern Philippines, 2013. Western Pacific Surveillance and Response Journal : WPSAR. https://doi.org/10.5365/wpsar.2015.6.4.007

Cunningham, R. M., Minard, C. G., Guffey, D., Swaim, L. S., Opel, D. J., \& Boom, J. A. (2018). Prevalence of Vaccine Hesitancy Among Expectant Mothers in Houston, Texas. Academic Pediatrics. https://doi.org/10.1016/j.acap.2017.08.003

Davis, K., Dickman, E. D., Ferris, D., \& Dias, J. K. (2004). Human papillomavirus vaccine acceptability among parents of 10- to 15-year-old adolescents. Journal of Lower Genital Tract Disease, 8(3), 188-194. https://doi.org/10.1097/00128360-200407000-00005

de Vries, R. D., Mesman, A. W., Geijtenbeek, T. B. H., Duprex, W. P., \& de Swart, R. L. (2012). The pathogenesis of measles. Current Opinion in Virology, 2(3), 248-255. https://doi.org/10.1016/j.coviro.2012.03.005

Dubé, E., Laberge, C., Guay, M., Bramadat, P., Roy, R., \& Bettinger, J. (2013). Vaccine hesitancy: An overview. In Human Vaccines and Immunotherapeutics. https://doi.org/10.4161/hv.24657

Dyer, O. (2019). Philippines measles outbreak is deadliest yet as vaccine scepticism spurs disease comeback. BMJ, 1739. https://doi.org/10.1136/bmj.1739

Giambi, C., Fabiani, M., D’Ancona, F., Ferrara, L., Fiacchini, D., Gallo, T., Martinelli, D., Pascucci, M. G., Prato, R., Filia, A., Bella, A., Del Manso, M., Rizzo, C., \& Rota, M. C. (2018). Parental vaccine hesitancy in Italy - Results from a national survey. Vaccine. https://doi.org/10.1016/j.vaccine.2017.12.074 
Gust, D., Brown, C., Sheedy, K., Hibbs, B., Weaver, D., \& Nowak, G. (2005). Immunization Attitudes and Beliefs Among Parents: Beyond a Dichotomous Perspective. American Journal of Health Behavior, 29(1), 81-92. https://doi.org/10.5993/AJHB.29.1.7

Hall, V., Banerjee, E., Kenyon, C., Strain, A., Griffith, J., Como-Sabetti, K., Heath, J., Bahta, L., Martin, K., McMahon, M., Johnson, D., Roddy, M., Dunn, D., \& Ehresmann, K. (2017). Measles Outbreak - Minnesota April-May 2017. MMWR. Morbidity and Mortality Weekly Report, 66(27), 713-717. https://doi.org/10.15585/mmwr.mm6627a1

Kim, S. S., Frimpong, J. A., Rivers, P. A., \& Kronenfeld, J. J. (2007). Effects of Maternal and Provider Characteristics on Up-to-Date Immunization Status of Children Aged 19 to 35 Months. American Journal of Public Health, 97(2), 259-266. https://doi.org/10.2105/AJPH.2005.076661

Larson, H. J., Jarrett, C., Eckersberger, E., Smith, D. M. D., \& Paterson, P. (2014). Understanding vaccine hesitancy around vaccines and vaccination from a global perspective: A systematic review of published literature, 2007-2012. In Vaccine. https://doi.org/10.1016/j.vaccine.2014.01.081

Larson Williams, A., Mitrovich, R., Mwananyanda, L., \& Gill, C. (2019). Maternal vaccine knowledge in low- and middle-income countries - and why it matters. Human Vaccines \& Immunotherapeutics, 15(2), 283-286. https://doi.org/10.1080/21645515.2018.1526589

Mohd Azizi, F. S., Kew, Y., \& Moy, F. M. (2017). Vaccine hesitancy among parents in a multiethnic country, Malaysia. Vaccine. https://doi.org/10.1016/j.vaccine.2017.04.010

Ochani, R. K., Yasmin, F., Tariq, A., \& Shaikh, A. (2019). Philippines hit by deadly measles outbreak - a wakeup call? Infezioni in Medicina, 3, 353-354.

Plotkin, S., Orenstein, W., Offit, P., \& Kathryn, M. E. (2018). Plotkin's Vaccines. In Plotkin's Vaccines. https://doi.org/10.1016/c2013-0-18914-3

Robichaud, P., Hawken, S., Beard, L., Morra, D., Tomlinson, G., Wilson, K., \& Keelan, J. (2012). Vaccine-critical videos on YouTube and their impact on medical students' attitudes about seasonal influenza immunization: A pre and post study. Vaccine, 30(25), 3763-3770. https://doi.org/10.1016/j.vaccine.2012.03.074

Shelby, A., \& Ernst, K. (2013). Story and science. Human Vaccines \& Immunotherapeutics. https://doi.org/10.4161/hv.24828

Takashima, Y., Schluter, W. W., Mariano, K. M. L., Diorditsa, S., de Quiroz Castro, M., Ou, A. C., Ducusin, M. J. U., Garcia, L. C., Elfa, D. C., Dabbagh, A., Rota, P., Goodson, J. L., \& Centers for Disease Control and Prevention (CDC). (2015). Progress toward measles elimination-Philippines, 1998-2014. MMWR. Morbidity and Mortality Weekly Report.

Walag, A. M. P., \& Fajardo, M. T. M. (2020). Rapid Assessment of the Perceived Impacts of an Adult-Education Science Competency-Based Enhancement Training on Alternative Learning System Mobile Teachers and Volunteer Teachers in Cagayan De Oro City, Philippines. Science International, 32(6), 605-608.

Walag, A. M. P., Gadian, D. C. C., Walag, I. P., Merlas, M. A. G., Larosa, L. V., Lumantas, S. P., \& Salugsugan-Joaquin, M. C. (2018). Adolescent Pregnancy and Family History of Adolescent Pregnancy in El Salvador City, Philippines. Canadian Journal of Family and Youth / Le Journal Canadien de Famille et de La Jeunesse, 10(1), 259-274. https://doi.org/10.29173/cjfy29351 
Wilson, S. L., \& Wiysonge, C. (2020). Social media and vaccine hesitancy. BMJ Global Health, 5(10), e004206. https://doi.org/10.1136/bmjgh-2020-004206

Yaqub, O., Castle-Clarke, S., Sevdalis, N., \& Chataway, J. (2014). Attitudes to vaccination: A critical review. Social Science \& Medicine, 112, 1-11. https://doi.org/10.1016/j.socscimed.2014.04.018

Yuen, C. Y. S., \& Tarrant, M. (2014). Determinants of uptake of influenza vaccination among pregnant women - A systematic review. In Vaccine.

https://doi.org/10.1016/j.vaccine.2014.06.067 